\title{
Ecological system influences in the treatment of pediatric chronic pain
}

\author{
Deirdre E Logan $\mathrm{PhD}^{1}$, Lisa Engle BKin BHSc PT², Amanda B Feinstein MS ${ }^{3}$, Christine B Sieberg PhD ${ }^{1}$, \\ Penny Sparling MSW RSW², Lindsey L Cohen $\mathrm{PhD}^{3}$, Caitlin Conroy PsyD ${ }^{1}$, \\ Dana Driesman BSc OT OT Reg(Ont) ${ }^{2}$, Akihiko Masuda $\mathrm{PhD}^{3}$
}

DE Logan, L Engle, AB Feinstein, et al. Ecological system influences in the treatment of pediatric chronic pain. Pain Res Manage 2012;17(6):407-411.

Family, school and the peer network each shape the chronic pain experience of the individual child, and each of these contexts also represents a domain of functioning often impaired by chronic pain. The goal of the present article is to summarize what is known about these bidirectional influences between children with pain and the social systems that surround them. Case reports that illustrate these complex, transactional forces and their ultimate impact on the child's pain-related functioning are included. A case involving siblings participating in an intensive interdisciplinary program for functional restoration and pain rehabilitation highlights how parents change through this treatment approach and how this change is vital to the child's outcomes. Another case involving a child undergoing intensive interdisciplinary treatment illustrates how school avoidance can be treated in the context of pain rehabilitation, resulting in successful return to the regular school environment. Finally, an acceptance and commitment therapy-focused group intervention for children with sickle cell disease and their parents demonstrates the benefits of peer contact as an element of the therapeutic intervention.

Key Words: Family; Pediatric pain; Peers; School

\section{Les influences d'un système écologique dans le traitement de la douleur chronique en pédiatrie}

La famille, l'école et le réseau de camarades façonnent l'expérience de douleur chronique de chaque enfant, et chacun de ces contextes représente un domaine de fonctionnement souvent perturbé par la douleur chronique. Le présent article vise à résumer ce que l'on sait de ces influences bidirectionnelles entre les enfants ressentant de la douleur et les systèmes sociaux qui les entourent. Les rapports de cas inclus illustrent ces forces transactionnelles complètes et leurs répercussions ultimes sur le fonctionnement de l'enfant lié à la douleur. Le cas d'une fratrie participant à un programme interdisciplinaire intensif pour le rétablissement fonctionnel et la réadaptation de la douleur fait ressortir à quel point les parents évoluent tout au long de cette démarche thérapeutique et à quel point ce changement est vital pour le sort de l'enfant. Un autre cas d'enfant qui subit un traitement interdisciplinaire intensif illustre comment on peut traiter l'évitement de l'école dans le contexte de la réadaptation de la douleur, au point de susciter un retour régulier en milieu scolaire. Finalement, une intervention de groupe axée sur la thérapie d'engagement et d'acceptation à l'intention d'enfants atteints d'anémie drépanocytaire et de leurs parents a démontré les bienfaits du contact avec des semblables comme élément de l'intervention thérapeutique.
$\mathrm{T}$ he individual exists within a network of social influences. The ecological model of human development first posed by Bronfenbrenner (1) suggests that multiple layers of influences shape children and their developmental course. Some of the most proximal forces are family, peers, and the classroom and school, all of which are described as elements of the 'microsystem' in Bronfenbrenner's ecological model because they are among the most integral components of the child's daily existence.

In recent years, we have advanced our understanding of how important these contextual influences are on the pediatric pain experience. Family, school and the peer network each shape the pain experience of the individual child or adolescent, and each also represents a domain of functioning that is often impaired by chronic pain. When working with children with complex chronic pain conditions, it is vital to look beyond the individual child and to incorporate these important contextual systems in both the assessment and treatment of pediatric chronic pain. The present article provides a brief overview of each of these key systems in which the individual child with chronic pain exists. Case examples are provided to illustrate the bidirectional forces between the individual child and the surrounding systems that ultimately influence the outcomes of the pediatric chronic pain experience.

FAMILY

According to the model described by Palermo and Chambers (2), family influences on pediatric chronic pain operate at several levels, from individual factors, such as parenting style or parental protective responses to pain, through dyadic influences such as the parent-child relationship, to family level variables such as the family environment. Each of these specific factors both influence and are influenced by pain and functional disability, with the ultimate outcomes of the chronic pain experience often modulated by other factors such as the child's characteristics, emotional distress and pain coping abilities.

A recent systematic review of the literature regarding family factors in pediatric chronic pain (3) yielded 16 studies that focused on associations between parent and family functioning and child pain outcomes. The most studied factors include family history of chronic pain, parental emotional distress, parental thoughts/behaviours related to pain (eg, parent pain catastrophizing, protective responses to pain), parent-child interactions and overall family environment and family functioning (eg, the extent of conflict, cohesion and expressiveness within the family). Many of these factors have been examined both as predictors of chronic pain and as outcomes altered by the existence of a child's pain within the family. A review by Lewandowski et al (3) published in 2008 concluded that the best evidence exists in support of an association between family functioning and pain-related disability, with better family functioning associated with lower levels of child disability in the face of chronic pain. Much of the research to date has been cross-sectional, leaving open questions about whether premorbid family functioning influences painrelated disability or vice versa. Most likely, these interactions are complex and transactional, as is illustrated in the following case example.

${ }^{1}$ Department of Psychiatry, Harvard Medical School and the Division of Pain Medicine, Department of Anesthesiology, Perioperative and Pain

Medicine, Children's Hospital, Boston, Massachusetts; ${ }^{2}$ Holland Bloorview Kids Rehabilitation Hospital, Toronto, Ontario; ${ }^{3}$ Department of

Psychology, Georgia State University, Atlanta, Georgia, USA.

Correspondence: Dr Deirdre E Logan, Pain Treatment Service, Children's Hospital Boston, 333 Longwood Avenue, Suite 549, Boston,

Massachusetts 02115, USA. Telephone 617-355-6694, fax 617-730-0199, e-mail deirdre.logan@childrens.harvard.edu 
Case 1: Family response to treatment of siblings with complex chronic pain

Given the significant impact of the family system on pediatric chronic pain outcomes, parent involvement in the treatment of complex pediatric pain is essential. The Mayo Family Pediatric Pain Rehabilitation Center (Massachusetts, USA), a partial hospital day treatment program for children with chronic pain, incorporates parents into the treatment model to address these complex relationships between family systems and child functioning. Treatment goals for parents include addressing parental responses to pain, helping parents to foster self-management of pain within their child, and addressing family dynamics and interactions regarding pain. The day treatment model provides a higher intensity of care and treatment coordination than can be afforded through outpatient services, while providing patients opportunities to rehearse the skills they are learning during nontreatment hours.

Eighteen-year-old 'Julie' and her 15-year-old brother 'Jack' presented with similar complaints of diffuse musculoskeletal pain symptoms, resulting in significant functional disability and high health care utilization. The case involving these siblings underscores the importance of parental intervention to restore functioning.

Demographics: Julie and Jack are white and come from a highly educated family. Both parents completed graduate school and the family resides in an affluent area. Education and career success were highly valued in this family.

Illness progression: Jack's pain symptoms began in 2009, shortly after his bar mitzvah, which he identified as a stressor in his life. Julie had experienced some pain symptoms before her brother's issues, but her own symptoms intensified with the onset of his symptoms. Both siblings also had notable psychological issues. From early adolescence, Julie struggled with anxiety, depression and 'focusing problems'. Jack also had a significant mental health history, including diagnoses of anxiety, obsessive-compulsive tendencies, attention deficit hyperactivity disorder (ADHD) and a long-standing difficulty with social skills.

At the time of evaluation for admission to the pain rehabilitation program, both siblings reported significant pain-related functional disability. Julie reported that her mother often spent $1 \mathrm{~h}$ to $2 \mathrm{~h}$ each morning assisting her out of bed to complete activities of daily living. Because of her pain, she had been out of school for two years. Jack had similar functional disability and fatigue. Similar to his sister, Jack had not attended school since 2009. Although he was supposed to receive daily tutoring, he often did not feel well enough to participate.

Parent functioning: There was a strong pattern of modelling and reinforcement of pain and illness behaviours in the family. Julie and Jack's mother had quit her job to remain at home with them after they became sick. While both parents displayed highly protective behaviour and distress as a result of their children's symptoms, the mother was more vocal about her own distress and the father more passive. The mother was also physically affectionate toward both children in ways that were more developmentally typical of younger child-parent interactions.

Interventions: Although both siblings had tried numerous interventions including medications, acupressure, physical therapy, chiropractic care and outpatient psychology, their symptoms were refractory to outpatient intervention. To avoid the dynamics of having siblings participate in the group-based program together, the siblings were admitted to the program sequentially. Jack's admission was contingent on Julie's success and the ability of their parents to carry over functional gains in the home setting after discharge.

The mother and father alternated their participation in the program. The goals of parent-based interventions at the pain rehabilitation program were to reduce parental catastrophizing around pain, to address excessive attention and emotionality toward the child's pain, and to reduce parental protective responses in the effort to foster the child's independence and positive coping. Julie and Jack's parents participated in a weekly open-format parent support group moderated by a staff psychologist, a structured psychoeducation group cotaught by a psychologist and nurse, and a physical and occupational therapy education group. Education groups covered such topics as the basic biology of pain and pain regulation, specific coping tools for pain management, successful transition back into the home setting following discharge and the rationale of the exercise-based treatment model. Three times per week, Julie and Jack's parents also directly observed their child during physical and occupational therapy sessions. The goals were to provide parents with one-on-one guidance for supporting their children's physical progress in the program and at home, to demonstrate the child's physical progress and to provide an opportunity for the therapist to model appropriate interactions around pain and pain behaviours. When possible, a psychologist joined these sessions to assist in this instruction. The parents were also provided with individual parent sessions with a staff psychologist to further support positive parenting strategies and help support parental changes in their responses to their child's pain. Furthermore, the family received one to three family therapy sessions per week with the child's primary program psychologist. The main goals of family therapy for each admission were: first, to provide psychoeducation to parents about functional restoration; second, to facilitate school reintegration plans; and finally, to explore long-standing family interaction patterns that had impacted the pain experience.

Both parents made progress from Julie's admission to Jack's admission in adopting better understanding of the distinction between acute and chronic pain. As with many parents in this program, learning not to protect their child from pain felt counterintuitive. It is often difficult for parents to embrace the concept of emphasizing functional restoration above pain reduction, despite clinical observations that this is the typical course of recovery. Embracing school reintegration can similarly feel overwhelming, as was the case for these parents. The mother had difficulty accepting that Julie was capable of attending school full-time. Julie should have graduated from high school the year of her admission; however, she was returning to school as a senior. Given the high value placed on academic success and achievement within this family, there may have been secondary gain contributing to the maintenance of pain and disability. For both the children and the parents, the symptoms provided an excuse for school avoidance and for lower than expected school achievement.

Adopting an acceptance-based treatment approach to family therapy (4), especially by exploring values, was effective in achieving the first two treatment goals. These techniques fostered a shift in the family's perspective from one of illness and pain to one of functioning. With regard to the third goal, there were significant issues with enmeshment and maladaptive family interaction patterns. Jack and his mother worked extensively in family therapy on addressing how their similar personality and temperament (eg, stubborn, argumentative, rigid) created conflict and often resulted in exacerbation of Jack's pain and symptoms. During the program, they both actively worked on establishing healthier communication patterns, both during family sessions and at home.

At present, Julie has completed one- and four-month postdischarge follow-up assessments and Jack has completed a one-month follow-up. While Julie still complains of "all over body aches" and fatigue, she is independent in daily activities and exercises three to four times per week. She is actively socializing with peers and taking a reduced set of classes to start her senior year. Jack is also physically active, seeing friends outside the home and attending school fulltime. During follow-up, it was evident that the entire family had shifted their behaviour. Instead of the family connecting around illness, they are all now going to the gym together. The intensive treatment model and the fact that Julie and Jack's parents underwent the program twice were crucial in altering this family's shared belief system around pain and illness, and decreasing the parents' distress and protective responses to their children, thus, fostering more adaptive coping in all family members. 


\section{SCHOOL}

School functioning, particularly school attendance, is well known to be impaired among many pediatric chronic pain sufferers. Existing research shows that many children with chronic pain miss extensive amounts of school, with several studies indicating that many of these children miss $50 \%$ or more of their school days $(5,6)$. Few studies have adequately investigated factors beyond attendance to provide a full understanding of the interactions between chronic pain and school functioning. Beyond school absence, chronic pain also appears to affect school performance (5) and children's sense of academic competence (7). Teachers and other school personnel frequently struggle to understand and respond to pain problems in the school setting (7). A recent review by Gorodzinsky et al (8) found 26 published studies on pediatric chronic pain that included school absence rates as an outcome, and 27 studies reporting some other single aspect of school functioning. However, only 14 studies examined two or more variables to provide a multidimensional picture of school impairment. In both the clinical and research domains, there is a need to obtain a more comprehensive understanding of school functioning in the context of pediatric pain.

School avoidance or 'school refusal' is one outcome emerging from the pediatric chronic pain experience that can be a challenging but necessary focus of intervention efforts. The following case example illustrates an innovative approach to targeting school avoidance and improving overall school functioning in children undergoing intensive interdisciplinary pain rehabilitation.

\section{Case 2: 'Get up and Go' to school. The Holland Bloorview} approach to chronic pain and school avoidance

Many children who experience chronic pain struggle with school attendance. Over time, this can lead to a school avoidance cycle. The cycle usually begins with unmanaged pain and fatigue. This, in turn, leads to decreased school attendance. The more school the child misses, the more likely the child is to experience anxiety, depression and/or social isolation as a result of falling behind in his or her coursework, losing connections with peers and being unable to cope with emerging challenges. These emotional and physical issues can often lead to further pain and fatigue and, ultimately, school avoidance. This was the case with 'Melissa'.

Melissa is a 14-year-old girl with a congenital orthopedic condition affecting both legs who has undergone multiple reconstructive surgeries. Following the final surgery, she experienced difficulty with pain control, which was never resolved and was eventually diagnosed as complex regional pain syndrome. She lost her ability to walk independently, becoming wheelchair dependent. She lacked regular structure in her day and had poor sleep hygiene. She presented with additional symptoms including headaches, stomachaches, anxiety and an overwhelming fear of failure and pain. Melissa did not like to ask for help and had a 'pleaser' personality. Over time, her school attendance decreased and she eventually stopped attending altogether.

Melissa is one of five siblings, three of whom have special needs. Her parents were experiencing marital strain and had contrasting parenting styles. Melissa felt the emotional weight of family stressors and did not feel supported by her family. Her mother appeared to encourage the 'sick role,' often prioritizing attending medical appointments over returning to normal life. Melissa had limited social interactions with friends due to pain, and her reduced school attendance further isolated her.

Melissa's school avoidance initially began with increased foot pain, which inhibited mobility. She stayed home from school more frequently due to leg pain that interfered with her sleep and her ability to focus at school. When Melissa did attend school, she would often come home early. She attempted to return to school but became anxious about connecting socially and her physical symptoms subsequently increased. Over a two-year period, she went from attending school full-time to partial days to no attendance with some home tutoring.
Melissa was admitted to Holland Bloorview Kids Rehabilitation Hospital in Toronto, Ontario, for a 10-week inpatient chronic pain program called 'Get up and Go'. The treatment includes school supports (teacher and community resource teacher), physiotherapy, occupational therapy, social work, nursing, a physician, therapeutic recreation and child life services. The program's guiding philosophy is to increase function and provide clients with coping strategies for symptom management. Interventions include a graded exercise program, a consistent daily schedule (including sleep and wake times), counselling, participation in a variety of recreational activities, regular school attendance on-site and a plan for community and school reintegration. Melissa's personal goals identified on admission were to return to school full time, eliminate her wheelchair use, improve sleep, climb stairs and abandon 'pain talk' mode (ie, a single-minded focus on pain symptoms in her thoughts and her verbal exchanges).

Melissa attended eighth grade at the on-site school, with a very small student-to-teacher ratio and teachers experienced in working with adolescents with chronic pain. Melissa's school attendance was gradually increased as her activity tolerance and coping ability improved. On admission, she was scheduled for short periods of school in the morning and afternoon with rest breaks in between, because this was all she could tolerate. With the support of the treatment team, Melissa gradually progressed to $17 \mathrm{~h}$ of school per week, in addition to an intensive therapy schedule, with appropriate accommodations in place. In conjunction with her child-life specialist, Melissa developed cue cards illustrating her coping strategies, including deep breathing, taking a walk, visualization and listening to music, which she tried in the Bloorview school before later using them in her community school.

On admission, each patient with chronic pain is assigned a community resource teacher (CRT) who acts as a liaison and advocate between the hospital school and the community school. The CRT, in collaboration with the team, assisted Melissa's transition back to her own school by advocating for personalized accommodations. During her admission, there were several family team meetings with the community school with the goals of providing education about chronic pain, making recommendations for accommodations and collaborating in designing a specific plan for school re-entry. Near discharge, Melissa attended her community school on several trial occasions. The team was then able to use feedback from Melissa and the school to overcome challenges and develop new strategies for school success. Melissa initially tried managing three courses, which appeared to increase her anxiety and pain. It was decided that two courses and two supported resource periods would assist with her coping, reduce stress and anxiety, allow her to pace her day and enable her to catch up on material previously missed. Other recommended accommodations for Melissa included a reduced course load, use of a resource room for extra help with assignments, photocopies of notes, extra time for tests and assignments, an extra set of text books, a locker near all classes, use of her coping kit in school, permission to leave class early to avoid crowds and extra help if she missed school due to a flare.

By the end of her admission, Melissa's overall functioning significantly improved. She returned to school full time, no longer required her wheelchair, became capable of climbing stairs and followed a consistent schedule including regular sleep and rise times. Melissa was no longer stuck in what she described as "the pain talk mode". After discharge from the inpatient program, the team, including the CRT, met with Melissa for follow-up every two weeks, then monthly, then as needed thereafter.

Some of the challenges faced in the program included addressing ongoing and unresolved family issues that are not necessarily resolvable over an eight-week period. The program is also limited by the family's willingness to change. In addition, while patients are often successful during the program, many experience periods of 'relapse' that can lead to recurrence of the school avoidance cycle. They may require further support or intervention during particularly high-risk times (eg, the start of school year, onset of illness or during times of 
stress). Due to limited resources, it can also be difficult to follow all program graduates on a long-term basis.

There are several benefits to providing an on-site school and a collaborative reintegration plan for return to school. The 'Get up and Go' program illustrates to children, families and schools that these children do have the ability to attend school consistently in spite of their symptoms. It provides a gradual supported return to school where various coping strategies can be attempted, resulting in increased confidence. The client feels supported with these accommodations and the community school is educated about chronic pain. This can decrease anxiety about return to school and reduce potential future school avoidance.

\section{PEERS}

Many pediatric chronic pain conditions have a peak age of onset in early to midadolescence, a developmental period that coincides with an increased emphasis on peer relationships. Relatively little is known, however, regarding the influences of peers on the pediatric pain experience. A recent descriptive systemic review by Forgeron et al (9) identified only nine studies focused on social functioning and peer relationships in children with chronic pain. These few studies support clinical observations that children in pain report fewer friendships, are subjected to more peer victimization, and are viewed by peers as more isolated and less likable than healthy peers. These patterns have been found across a number of pain conditions, with studies focusing on headache, abdominal pain, fibromyalgia, arthritis and sickle cell disease. One study compared children with chronic pain with previously published research on children with other types of chronic illness, and concluded that chronic pain interferes more extensively with peer relationships compared with other types of chronic conditions (10).

Several studies have highlighted the protective effects of positive peer relationships, showing that children with positive peer relationships reported less pain and greater perceived social competence. This finding has clinical relevance because it suggests that if children with pain can be assisted in making or maintaining strong social connections with peers, these relationships may serve as a buffer to mitigate negative outcomes of the pediatric chronic pain experience. One way to counteract the social isolation and decreased positive peer experiences reported by children with chronic pain is to facilitate connections and treatment experiences that have a peer group component. Group treatments, whether specific to a particular pain condition or more generally targeted toward the management of all types of pain, have numerous benefits to participants, including increasing the child's sense of social support, decreasing isolation, and allowing opportunities to rehearse and refine social skills that can transfer back to interactions with healthy peers.

Clinical experience and growing research (11) also show that parents similarly benefit from connecting with other parents of children with chronic pain. Often parents are most effective at helping one another to understand how to respond to pain behaviours in ways that encourage adaptive functioning. The following case example illustrates the benefits of providing pain intervention in the group context, wherein both children and parents can benefit from the support of peers who have experienced similar pain issues.

\section{Case 3: Group-based intervention for sickle cell disease}

Clinical experience and research, although scarce, demonstrate that most psychological interventions for youth with sickle cell disease (SCD) are conducted with individual patients and may include family members. Peers, however, are rarely included. These interventions typically target pain, one of the most common and debilitating symptoms of SCD. Pain has been demonstrated to be associated with a range of psychosocial problems, including school absences and diminished time with peers (12). There is a pressing need for effective and practical approaches to help adolescents with SCD pain improve their functioning and quality of life $(13,14)$. Given the impact of pain on social functioning and peer relationships in youth with chronic or recurrent pain, it is important to find strategies for incorporating peer contact and support into such approaches.

Acceptance and commitment therapy (15) is a psychological treatment that has garnered empirical support for adults (15) and adolescents (4) with chronic pain, and can be conducted in both individual (15) and peer-group formats (16). This approach encourages self-awareness and acceptance of difficult internal experiences (eg, fear, pain) while promoting identification and pursuit of personally meaningful values and goals (eg, attending school, interacting with peers). Recently, this approach was conducted via eight individual therapy sessions to successfully treat an adolescent with SCD and pain (17). To incorporate peer support and provide the acceptance and commitment therapy efficiently, the program by Masuda et al (17) was adapted to a one-day peer-group workshop format lasting approximately $4 \mathrm{~h}$.

The group enrolled three adolescent females with SCD, 'Annie' (12 years of age), 'Bess' (14 years of age) and 'Cindy' (17 years of age). Bess was accompanied by her mother and father; Annie and Cindy were accompanied by their mothers only. With regard to pain histories, Annie had experienced only mild pain before this year, when she experienced her first vaso-occlusive pain crisis followed by three additional pain crises. After her second pain crisis, she began catastrophizing, or thinking negatively about future pain, which was exacerbated by her mother's high anxiety about her SCD. Bess had a history of pain crises and related hospitalizations since early childhood. Bess and her parents had experience managing her symptoms (ie, fatigue and pain) so that she remained active and engaged in important activities, but they reported being variably successful. Bess often struggled with feeling as though her family members could not relate to her experiences living with SCD. Cindy maintained a relatively healthy childhood, experiencing only two pain crises, neither of which required hospitalization. When Cindy began puberty at age 13, the frequency of her pain crises increased, requiring occasional hospitalization. She reported worrying about her crises increasing in intensity and frequency.

At the workshop, all three adolescents reported functional disability related to their pain and fatigue. Annie wanted to swim with her friends, but her mother worried that the water or temperature changes following swimming might exacerbate her pain. Bess wanted to try out for cheerleading but was afraid that she might become overly fatigued and dehydrated. Cindy wanted to start taking steps toward improving her grades and applying for college but was concerned that pain would interfere with studying and completing college applications. The workshop included discussion and experiential exercises focused on clarifying personal values (eg, health, academics, friendships), targeting the barriers (eg, fear, pain) to living consistently with these values and setting goals to bring life in line with values (eg, increasing study time to improve the likelihood of admission into college). The interactive nature of the group intervention allowed peers to support and encourage one another. Cindy suggested that Bess discuss her SCD with the cheerleading coach, bring ample water to practice and join the cheerleading squad. Because Cindy was older and had first-hand experience successfully managing a similar situation in the past, Bess felt very encouraged by Cindy's suggestions. Bess also felt that Cindy understood her experience, which helped her to feel 'not so alone'. Both Bess's and Cindy's parents problem-solved around Annie's mother's anxiety about swimming (eg, swim shirt, indoor pools) and encouraged her to allow Annie to swim. Bess's mother was able to share concrete examples related to Bess's experiences participating in sports and how she worked with the coaches and other parents to accommodate Bess's health care needs. Although they were younger, Annie and Bess helped Cindy set concrete goals to improve her studying despite pain interfering with these efforts. Annie suggested that Cindy take no longer than 10 min 'distraction study breaks' when she has pain or fatigue and then to return to her studies regardless of whether her pain was successfully reduced. Bess suggested that, "You know we cannot control the pain, but you can sit down and study." At the conclusion of the workshop, the adolescents 
and the mothers all chose to exchange contact information to stay in touch.

Participants were followed-up one month after the workshop at their individual medical appointments. They reported continued progress on their individual goals. Bess reported maintaining contact with Cindy following the group and consulting with her again before contacting the cheerleading coach to discuss trying out for the squad. Cindy had developed better study habits and reported that pain was no longer a barrier. She acknowledged that she frequently thought back to the group and the advice she received. Although she continued to experience pain, she realized that the pain is "the same" regardless of whether she is studying. Annie's mother reported that she has kept in touch with the other mothers, and is working to be less protective of Annie. She reported that this continues to be a struggle, but the other mothers are a significant support. In summary, the one-day workshop with Annie, Bess, Cindy and their parents demonstrated the importance of peers in helping to identify and implement strategies around living with pain, as well as in helping to provide support within the context of the workshop and following its conclusion.

\section{REFERENCES}

1. Bronfenbrenner U. Toward an experimental ecology of human development. Am Psychol 1977;32:513-31.

2. Palermo TM, Chambers CT. Parent and family factors in pediatric chronic pain and disability: An integrative approach. Pain 2005;119:1-4.

3. Lewandowski AS, Palermo TM, Stinson J, Handley S, Chambers CT. Systematic review of family functioning in families of children and adolescents with chronic pain. J Pain 2010;11:1027-38.

4. Wicksell RK, Melin L, Lekander M, Olsson GL. Evaluating the effectiveness of exposure and acceptance strategies to improve functioning and quality of life in longstanding pediatric pain: A randomized controlled trial. Pain 2009;141:248-57.

5. Logan DE, Simons LE, Kaczynski KJ. School functioning in adolescents with chronic pain: The role of depressive symptoms in school impairment. J Pediatr Psychol 2009;34:882-92.

6. Sato A, Hainsworth K, Khan K, Ladwig R, Weisman S, Davies W. School absenteeism in pediatric chronic pain: Identifying lessons learned from the general school absenteeism literature. Child Health Care 2007;36:355-72.

7. Claar RL, Walker LS, Smith CA. Functional disability in adolescents and young adults with symptoms of irritable bowel syndrome: The role of academic, social, and athletic competence. J Pediatr Psychol 1999;24:271-80.

8. Gorodzynsky AY, Hainsworth KR, Weisman SJ. School functioning and chronic pain: A review of methods and measures.

J Pediatr Psychol 2011;36:991-1002.

9. Forgeron PA, King S, Stinson JN, McGrath PJ, MacDonald AJ, Chambers CT. Social functioning and peer relationships in children

\section{CONCLUSIONS}

The preceding case examples highlight the salience of the various system-level influences on the child's chronic pain experience, illustrating a few of the many ways that pediatric pain is both shaped by and, in turn, shapes the important individuals who surround the child. The family, school and peer contexts are central to every child's development. Health care providers working with children with chronic pain should strive to find ways to incorporate the people and environments within the child's microsystem into the treatment of pediatric pain. In many cases, developing and delivering interventions that focus on these systemic forces is the most effective route to fostering positive and lasting improvements in the functioning and wellbeing of children experiencing complex chronic pain.

ACKNOWLEDGEMENTS AND SOURCES OF SUPPORT: The authors thank the Health Resources and Service Administration, Pain in Child Health training consortium, MayDay Fund, and the Sara Page Mayo fund for pediatric pain research at the Children's Hospital Boston Division of Pain Medicine.

and adolescents with chronic pain: A systematic review. Pain Res Manag 2010;15:27-41.

10. Konijnenberg A, Uiterwaal C, Kimpen J, van der Hoeven J, Buitelaar J, de Graeff-Meeder E. Children with unexplained chronic pain: Substantial impairment in everyday life. Arch Dis Childhood 2004;90:680-6.

11. Logan DE, Simons LE. Development of a group intervention to improve school functioning in adolescents with chronic pain and depressive symptoms: A study of feasibility and preliminary efficacy. J Pediatr Psychol 2010;35:823-36.

12. Palermo TM, Schwartz L, Drotar D, McGowan K. Parental report of health-related quality of life in children with sickle cell disease. J Behav Med 2002;25:269-83.

13. Anie K, Green J. Psychological therapies for sickle cell disease and pain. Cochrane Database Syst Rev 2002(2):CD001916.

14. Chen E, Cole SW, Kato PM. A review of empirically supported psychosocial interventions for pain and adherence outcomes in sickle cell disease. J Pediatr Psychol 2004;29:197-209.

15. Hayes S, Strosahl K, Wilson K. Acceptance and Commitment Therapy: An experimental approach to behavior change. New York: Guilford Press, 1999.

16. Blackledge JT, Hayes SC. Using Acceptance and Commitment training in the support of parents of children diagnosed with autism. Child Fam Behav Ther 2006;28:1-18.

17. Masuda A, Cohen LL, Wicksell RK, Kemani MK, Johnson A. A case study: Acceptance and commitment therapy for pediatric sickle cell disease. J Pediatr Psychol 2011;36:398-408. 


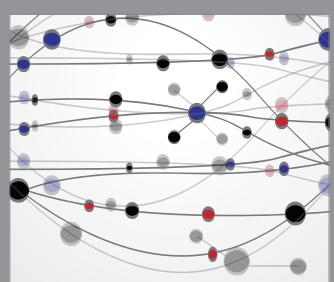

The Scientific World Journal
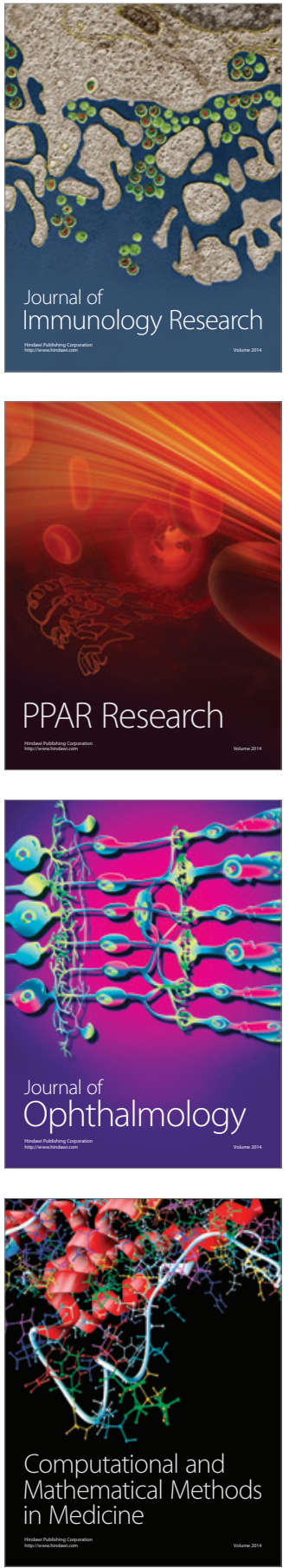

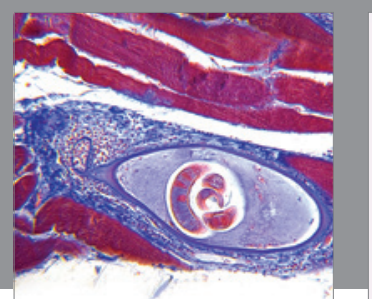

Gastroenterology Research and Practice

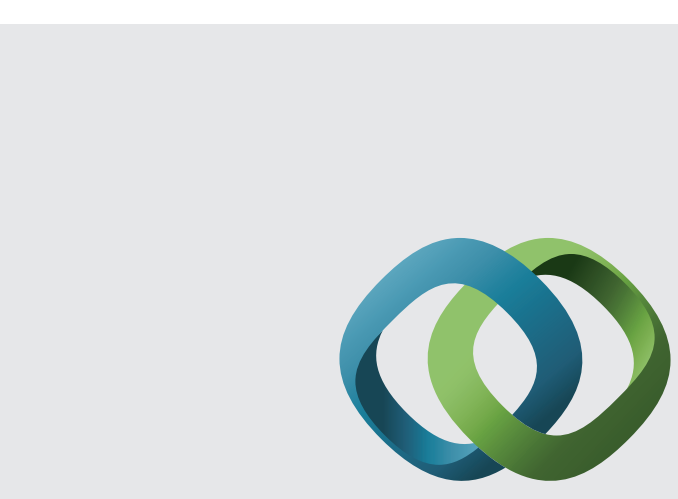

\section{Hindawi}

Submit your manuscripts at

http://www.hindawi.com
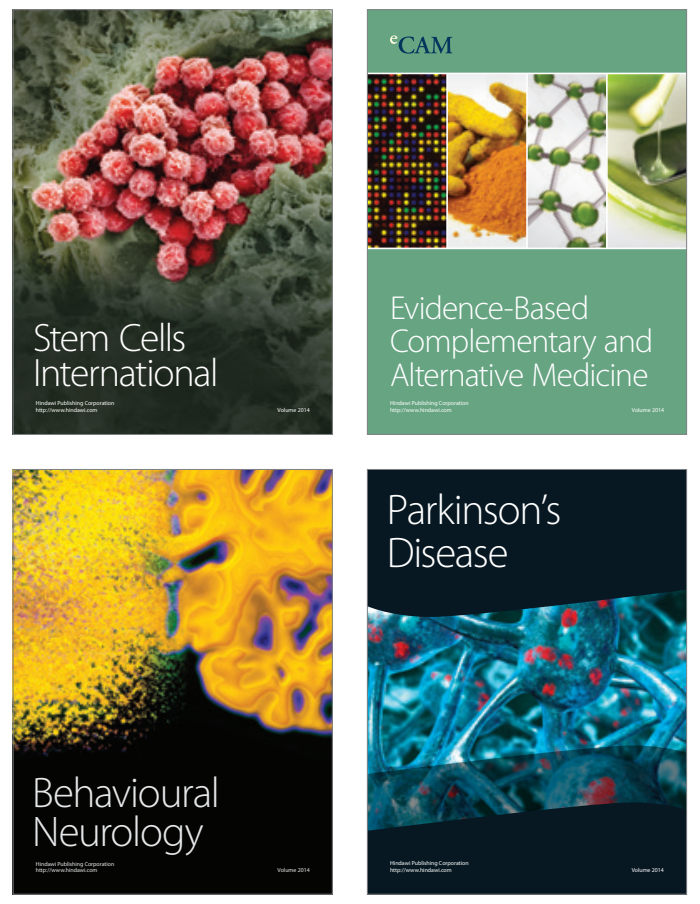
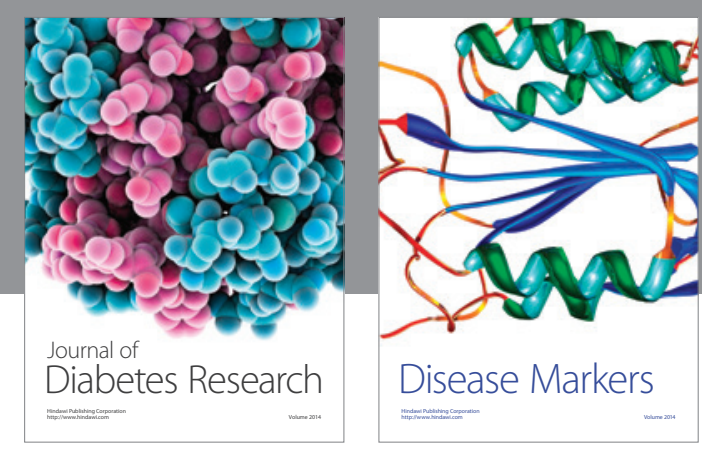

Disease Markers
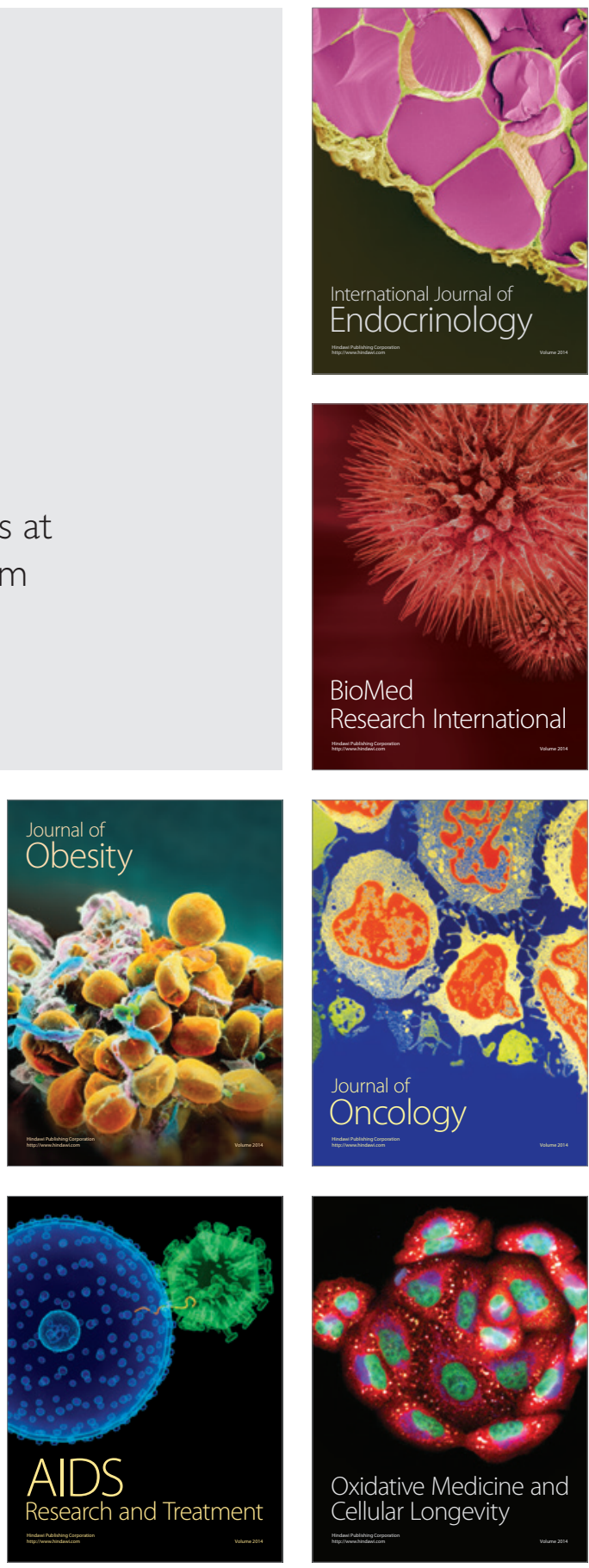